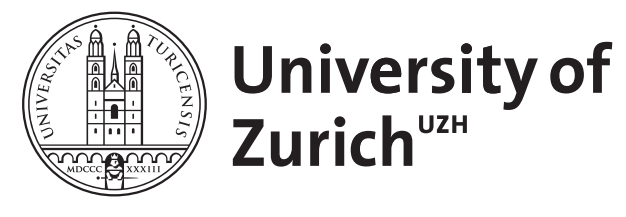

\title{
Trait cheerfulness and the sense of humour
}

\author{
Ruch, Willibald ; Carrell, Amy
}

\begin{abstract}
The present paper examines the hypothesis thar trait cheerfulness, seriousness, and bad mood form the temperamental basis of the sense of humour. American( $\mathrm{N}=263)$ and German $(\mathrm{N}=151)$ adults filled in the state-trait cheerfulness inventory and a sense of humour scale. Correlations between the two inventories showed that trait cheerfulness accounted for most of the variance-in the sense of humour scales with seriousness and bad mood displaying some incremental validity. The sense of humour subscales and the facets of cheerfulness formed a potent first factor in a joint factor analysis of the subscales of the two inventories. While seriousness and playfulness-recently proposed as being the basis of the sense of humour-were indeed related to the sense of humour scales: they contained additional variance and loaded on the subsequent factors of trait seriousness and bad mood. The results are discussed in the context of the necessity of separating affective and mental factors in the sense of humour. (C) 1998 Elsevier Science Ltd. All rights reserved.
\end{abstract}

DOI: https://doi.org/10.1016/S0191-8869(97)00221-3,

Posted at the Zurich Open Repository and Archive, University of Zurich

ZORA URL: https://doi.org/10.5167/uzh-77538

Journal Article

Originally published at:

Ruch, Willibald; Carrell, Amy (1998). Trait cheerfulness and the sense of humour. Personality and Individual Differences, 24(4):551-558.

DOI: https://doi.org/10.1016/S0191-8869(97)00221-3, 
This manuscript was published as:

Ruch, W., \& Carrell, A. (1998). Trait cheerfulness and the sense of humor.

Personality and Individual Differences, 24, 551-558. 


\title{
TRAIT CHEERFULNESS AND THE SENSE OF HUMOUR
}

\author{
Willibald Ruch \\ Heinrich-Heine-University of Düsseldorf \\ and \\ Amy Carrell \\ University of Central Oklahoma
}

Running Head: Trait cheerfulness and the sense of humour

Author's address:

PD Dr. Willibald Ruch, Department of Physiological Psychology, Heinrich-Heine-University of Düsseldorf, Universitätsstraße 1, 40225 Düsseldorf, Germany.

Phone: office: x49-211-81-13067 or 12065; home: x49-211-376363

FAX: x49-211-81-12856; e-mail: wruch@uni-duesseldorf.de 
Summary - The present paper examines the hypothesis that trait cheerfulness, seriousness, and bad mood form the temperamental basis of the sense of humour. American $(\underline{N}=263)$ and German $(\underline{N}=$ 151) adults filled in the state-trait cheerfulness inventory and a sense of humour scale. Correlations between the two inventories showed that trait cheerfulness accounted for most of the variance in the sense of humour scales with seriousness and bad mood displaying some incremental validity. The sense of humour subscales and the facets of cheerfulness formed a potent first factor in a joint factor analysis of the subscales of the two inventories. While seriousness and playfulness--recently proposed as being the basis of the sense of humour--were indeed related to the sense of humour scales, they contained additional variance and loaded on the subsequent factors of trait seriousness and bad mood. The results are discussed in the context of the necessity of separating affective and mental factors in the sense of humour. 


\section{TRAIT CHEER RLNESS AND THE SENSE OF HUMOUR}

Recently, a state-trait model of cheerfulness, seriousness, and bad mood was introduced, and an instrument (the State-Trait-Cheerfulness Inventory; STCI) to measure the three concepts both as states and temperamental traits was constructed (Ruch, Köhler \& van Thriel, 1996). While the utility of these concepts was not meant to be restricted to the realm of humour, it was postulated that they account for interindividual differences in humour-related behaviour and experience in a variety of ways (Ruch \& Köhler, in press a). The prediction of behaviour in experiments as well as the study of the relationship between these traits and the sense of humour may provide support for the postulate that trait cheerfulness, seriousness, and bad mood form the temperamental basis of humour.

The relationship between cheerfulness and sense of humour is controversial, however. Typically these two constructs are discussed separately from each other with little reference to the other concept, and sometimes even no relationship is seen between them. Nevertheless, some authors have dealt with both concepts and therefore needed to speculate about their relationship. The type of relationship postulated depends partly on what is understood by "humour," i.e. whether "humour" is understood as a collective term for all phenomena of the comic or used in its narrow meaning (and different from jokes, comic, irony, satire etc.).

Cheerfulness and humour (narrow). Lersch (1962), a representative of the latter position, considered humour to be a world view. A person with a humourous attitude is someone who understands the insufficiencies and shortcomings of life and fellow humans but also tolerates and forgives them rather than pokes fun at them. "Humourless" is the person who dwells on the insufficiencies of existence and weaknesses of fellow humans. Taking oneself too seriously and not being able to laugh at oneself, or distance from one's problems are further indicators of humourlessness. While Lersch considered humour and cheerfulness as being distinct from each other, the former was based on the latter. Although Lersch did not further elaborate exactly how humour originates from cheerfulness (or is based on it), others added that a humourous world view is a sign of human maturity, an attitude akin to wisdom, and developed on prior suffering, pain, and exposure to an imperfect world (Hehlmann, 1968).

Although not explicitly stated by Lersch, it appears from his writings that seriousness, another category of world views, is involved in humour as well. Lersch argued that while humour is based on cheerfulness, it is serious as well in that it contains the wisdom that nothing earthly and human is perfect. In this respect, humour is different from merriment/hilarity. The former is contemplative, pensive, and profound, the latter thoughtless, superficial, and shallow (Lersch, 1962). This view allows the hypothesis that humour (in its narrow sense) is a blend of cheerfulness (as a temperament or prevalent mood) and seriousness (as a mental quality). No empirical test of these hypotheses has been undertaken so far, primarily because no measure for such a conceptualization of the sense of humour is available. 
Cheerfulness and humour (broad). When humour is understood in its broad meaning, further relationships can be pointed out. Most current scales of sense of humour emphasize elements like the tendency to smile or laugh in a variety of situations, a general carefreeness or lightheartedness, the frequent initiation of merry interactions and enjoyment of entertaining others, and the liking and positive evaluation of stimuli, situations and roles that make one laugh. It was pointed out that such conceptualizations make sense of humour appear to be aspects of facets of Extraversion, such as surgency or cheerfulness (Köhler \& Ruch, 1996).

Despite the large amount of conceptual overlap between trait cheerfulness and current conceptualizations of sense of humour, one should not treat them as interchangeable because the overlap is far from being perfect. For example, defining aspects of cheerfulness, such as a prevalent cheerful or positive mood typically are missing in the sense of humour scales. Furthermore, habitual individual differences in humour behaviour and experience have been shown to be multi- not unidimensional (Craik, Lampert \& Nelson, 1996; Köhler \& Ruch, 1996). Thus, cheerfulness, at best, can be seen to form only one component of the sense of humour. Indeed, other factors are needed to account for further forms of humour (in the broad sense), either alone or in combination with cheerfulness. For example, the above mentioned distinction of humour (and cheerfulness) from merriment/hilarity by qualities involving seriousness (or the lack of it) allows the hypothesis that the more shallow forms of humour are blends of cheerfulness and low seriousness. In other words, it will be the high cheerful/low serious person who laughs at slapstick, shallow comedies, practical jokes, etc.

Confirmation for the proposed relationship between sense of humour in the broader sense and cheerfulness and seriousness comes from recent factor analytic studies (e.g. Köhler \& Ruch, 1996). For example, a joint factor analysis of 13 subscales of sense of humour inventories and 11 facets of trait cheerfulness and seriousness confirmed that all sense of humour scales and the facets of cheerfulness merge in a potent first factor (Köhler \& Ruch, 1996). However, while they shared a common loading on the cheerfulness factor, they differed with respect to whether they are also loaded by (low) seriousness, the second factor, and how marked this loading is. While the more affect-related humour scales were close to the axis, the sense of humour scales involving mentality or attitudes were additionally loaded negatively by seriousness and thus located in the cheerfulness/low seriousness quadrant.

The present study examines further the relationship between trait cheerfulness and sense of humour. The recent conceptualization of the sense of humour by McGhee (1996) is chosen for several reasons. First, it has an explicated theoretical background. Second, it splits the sense of humour construct into several components, thus allowing the study of the relationship between cheerfulness and different facets of humour, some of them relevant to test Lersch's assertions. Third, while conceptualizations of the sense of humour typically treat the concept as unipolar, McGhee's model also pays attention to forms of humourlessness. 


\section{A model of the sense of humour}

While McGhee (1979) did not find the concept of sense of humour necessary or fruitful for the study of humour, in more recent years he has presented a multi-faceted concept of the sense of humour (McGhee, 1996). For McGhee (1979), humour is a form of play - the play with ideas. Without a playful frame of mind, the same event is seen as interesting, puzzling, annoying, frightening, etc., but not as funny. Not surprisingly, playfulness and its counterpart, seriousness, were assigned core roles in that model of sense of humour (playfulness and seriousness are considered to be somehow antagonistic but form separate components of the model). While people might be very good at spotting the incongruities, absurdities, and ironies of life, only the mentally playful will find humour in them while those with a serious attitude or frame of mind will not treat them humourously. Therefore, playfulness is seen as the foundation of the sense of humour.

While playfulness is seen to form the basis for the sense of humour, it is not a quality specific to humour. Six other facets represent more genuine humour skills and humour behaviour and relate to individual differences in the fields of enjoyment of humour, laughter, verbal humour, finding humour in everyday life, laughing at yourself, and humour under stress. McGhee (1996) assumes that while children inherit playfulness, influences of socialization counteract it and may cause a shift into seriousness making individuals lose their ability to be playful. Again, the rediscovery of a playful attitude or outlook is a key element for change; its activation triggers the other components.

The sense of humour scale (SHS; McGhee, 1996) is a rationally developed scale designed to assess the eight components of the sense of humour as well as a "humour quotient," the latter being a total score computed by adding the subscales giving laughing at yourself and humour under stress higher weights (1.5 and 2, respectively). This is based on the yet untested assumption that the latter two skills are more difficult to develop than the others. Likewise there is no empirical evidence yet for the basic assumptions that the proposed components of the sense of humour are homogeneous and that the playfulness (and low seriousness) are "motors" for the other components of the sense of humour.

\section{The present study}

The present study is aimed at testing hypotheses regarding the relationship between McGhee's conceptualization of the sense of humour and trait cheerfulness, seriousness, and bad mood in two samples. There are grounds to expect that trait cheerfulness will predict all facets subsumed by McGhee (1996) under "sense of humour". Part of this relationship is trivial due to the conceptual overlap between trait cheerfulness and some facets of sense of humour (in the broad sense). However, there also are conceptual relationships with the more 'difficult' humour skills sensu McGhee, namely 'laughing at yourself' and 'humour under stress' (at least the former of them counting as indicators of humour in the more narrow 
sense). It has been demonstrated that trait cheerfulness represents a predominance of cheerful mood; the thresholds for coming into cheerful mood are lowered, and trait cheerful individuals can't be brought out of that mood as easily as low cheerful people can (Ruch \& Köhler, in press b). Hence, one might stretch this tendency to hypothesize that highs (as compared to lows) are more likely to maintain good mood when under stress or when facing adverse circumstances (humour under stress). They also may maintain longer in a state that allows them to poke fun at certain physical qualities of themselves, telling others about the funny sides of their own blunders or embarrassing incidents, or joining laughter when they are the target of the laughter (suggesting a correlation with 'laughing at yourself').

As regards trait seriousness and bad mood, it is expected that they will be predictive as well. Seriousness might be involved in 'laughing at yourself' (incremental to cheerfulness) and is expected to correlate positively with facet 2 (seriousness and negative mood) and negatively with facet 3 (playfulness and positive mood). Nor surprisingly, it is expected that trait bad mood and 'seriousness and negative mood' will correlate highly. Thus, because of their broad scope, more complex relationships are expected for the core facets of McGhee's model.

\section{ME T H O D}

\section{Subjects and procedure}

American sample. Subjects were 263 adult volunteers, mainly undergraduate students (103 men and 160 women) at the University of Central Oklahoma. Subjects were tested in small groups during class. Mean age was 25.83 years $(\underline{\mathrm{SD}}=10.33$; range 17 to 64 years).

German sample. This sample included 151 paid German adults (68 men and 83 women) from 18 to 65 years of age $(\underline{M}=33.06, \underline{S D}=11.62)$. They were heterogeneous with respect to sociodemographic variables. About one third of them were students tested in the university; the others were adults of different professions who filled in the questionnaires at home during.

\section{Instruments}

$\underline{\text { SHS. }}$. The sense of humour scale (SHS; McGhee, 1996) is a 40-item questionnaire in a four-point answer format ( $1=$ strongly disagree; 4 = strongly agree $)$ aimed at measuring the sense of humour and its eight components (sensu McGhee), namely enjoyment of humour (SHS-1), seriousness and negative mood (SHS-2), playfulness and positive mood (SHS-3), laughter (SHS-4), verbal humour (SHS-5), finding humour in everyday life (SHS-6), laughing at yourself (SHS-7), and humour under stress (SHS-8). The order of items was changed from a blockwise presentation to one in which items alternate according to the order of scales. Also, a simple total score was derived by adding the subscales (after reversing the second 
scale) rather than weighting them. The German sample answered a translation of the SHS.

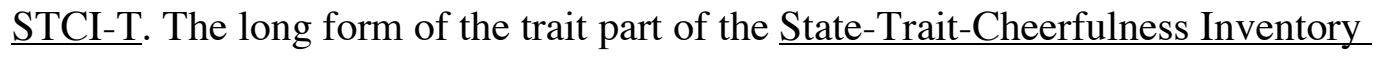
(STCI-T; Ruch et al., 1996) is a 106-item questionnaire in a 4-point answer format providing scores for the three traits of Cheerfulness (STCI-T CH; 38 items), Seriousness (STCI-T SE; 37 items), and Bad Mood (STCI-T BM; 31 items) and their 5, 6, and 5 definitional components, respectively. The American sample completed the international pilot version of the trait part.

\section{R E S U L T S}

Psychometric characteristics of the STCI and SHS-scales in the two samples. Means, standard deviations, and Cronbach Alpha of the different scales and their intercorrelation with sex and age were computed and are given in Table 1.

Insert Table 1 about here

Table 1 shows that Cronbach Alpha's of the SHS-subscales (having 5 items each) ranges from 0.57 to 0.80 (Median $=0.70$ ) and from 0.56 to 0.78 (Median $=0.73$ ) in the American and German samples, respectively. SHS-7 (Laughing at yourself) had the highest variance and also the highest Alpha. The SHS-total score and the STCI-T scales have good internal consistency in both samples. The assertions about 'difficulty' of humour skills are only partly confirmed on the basis of the present set of items. While SHS-8 (humour under stress) had indeed the lowest mean in the US sample, it was only second in the German sample. SHS-7 (laughing at yourself) has the fifth and fourth lowest mean in the US and German samples, respectively.

Sex and age differences. While there was no consistent gender difference in the SHS, females scored higher on STCI-T cheerfulness in both samples ( $\underline{r} \mathrm{~s}=0.20$ and $0.17 ; \mathrm{P}<0.05$ ). However, at the level of facets, the only consistent gender effect was found for $\mathrm{CH} 2$ (i.e. females indicated that they laugh more often and more easily than the males did; $\underline{\mathrm{r} s}=0.027$; both $\mathrm{P}<0.001$ ). Age correlated negatively with SHS-5 (enjoying verbal humour; $\underline{\mathrm{r}}=-0.30$; $\mathrm{P}$ $<0.001$ ) and SHS-6 (finding humour in everyday life; $\underline{\mathrm{r}}=-0.20 ; \mathrm{P}<0.05$ ) and positively with STCI trait seriousness in the German sample $(\underline{r}=0.26 ; \mathrm{P}<0.01)$; the American sample seems to be too homogeneous to expect age differences to occur.

Sample differences. While means of the two samples were significantly different for 9 of the 12 scales $(\mathrm{P}<0.01)$, most of the differences were due to the different ages of the subjects of the two samples. Therefore, a 2 x 2 (gender by sample) ANOVA was computed for the age group of 21 to 30 years only, i.e. the sub-sample homogeneous with respect to age but still large enough for analysis (69 Germans, 79 Americans). Here the German sample scored lower in SHS-H1, SHS-H5, and SHS-H6.

Internal structure of the SHS in the two samples. There were only positive 
intercorrelations among the scales (after SHS-2 was reflected), which were significant in all but one case. A factor analysis of the scales suggests that the SHS is not unidimensional. While in both samples a strong general factor (with loadings ranging from 0.49 to 0.85 ) emerged that accounted for 54\% (US) and 47\% (German) of the variance, there was also a second unrotated factor (eigenvalues 0.99 and 1.09) loaded by the core facets SHS-2 (0.69; $0.75)$ and SHS-3 (-0.49; -0.43). Oblique rotations yielded factors of 'humour skills' (facets 1 and 4 to 8 ) and 'playful vs. serious' (facets 2 and 3 ) which, however, were highly correlated in the US (0.64) and German (0.54) sample.

Joint factor analysis of the subscales of the SHS and STCI-T in the two samples. The 16 facets of the STCI-T and the subscales of the SHS were intercorrelated and subjected to a factor analysis in the two samples separately. The scree test suggested the retention of three factors in both samples (explained variance, US: 64.5\%; German: 61.1\%) which were obliquely rotated. The reference structure is presented in Table 2.

Insert Table 2 about here

Factor 1 ('cheerfulness/sense of humour') was loaded by the sense of humour scales of the SHS and the facets of trait cheerfulness. Thus, this factor merged elements, like enjoying humourous stimuli (SHS-1, STCI-T CH4), finding humour in everyday life (SHS-6) and even in one's own mishaps (SHS-7), enjoying cheerful interactions (STCI-T H5) and telling jokes (SHS-5), a tendency to laugh (SHS-4, STCI-T CH2), prevalence of cheerful mood (STCI-T $\mathrm{CH} 1$ ), and the use of humour under stress (SHS-8).

Factor 2 ('seriousness') was loaded by all facets of seriousness; however, neither SHS-2 (seriousness and negative mood) nor SHS-3 (playfulness and positive mood) loaded on it ${ }^{1}$. Factor 3 ('bad mood') was loaded positively by five facets of bad mood and by SHS-2 (seriousness and negative mood) and negatively by SHS-3 (playfulness and positive mood) but also the STCI-facets of cheerful mood and composedness. (The latter effect typically occurs when cheerfulness and bad mood are too strongly negatively correlated). The factor of cheerfulness correlated negatively with seriousness (US: -0.40; German: -0.34) and bad mood (US: -0.62; German: -0.38), the latter being positively correlated (US: 0.52; German: 0.14).

Correlation between the SHS and the STCI-T. The relationship between trait cheerfulness and the SHS-subscales and total scale was examined next. As expected, in both samples trait cheerfulness correlated significantly and highly with all facets of the sense of humour. The size of the correlations ranged from 0.52 (laughing at yourself) to 0.65 (playfulness and positive mood; laughter) in the American sample and from 0.47 (humour under stress) to 0.75 (playfulness and positive mood) in the German sample (all $\mathrm{P}<0.001$ ). The correlation between trait cheerfulness and the SHS-total score of sense of humour was 0.80 and 0.83 in the US and German samples, respectively; these coefficients are not much lower than the reliability of the scales. The correlation with the total score of the six humour skills is very 
high (.74 in both samples), too, indicating that the two concepts might be essentially identical.

The correlation coefficients for 'laughing at yourself' (SHS-7), the indicator of sense of humour in the narrow sense, were among the lowest (app. 0.50) obtained suggesting that there might indeed be further factors, such as seriousness, needed for a better prediction. The stepwise regression analysis, however, indicated no incremental validity for the seriousness total score. Since trait seriousness proved to be a heterogeneous concept, it may well be that some facets might be positively correlated. Thus, a stepwise regression analysis was computed for the German sample with trait cheerfulness and the facets of seriousness as predictors and SHS-7 as the criterion. Indeed, in addition to cheerfulness, two seriousness facets entered the regression equation with both a negative (step 2: SE5; -0.32) but also positive (step 3: SE2; 0.18) weight $\left(\mathrm{F}[3,147]=20.63 ; \mathrm{P}<0.0001 ; \mathrm{r}_{\text {mult }}=0.54\right)$. Thus, 'laughing at yourself' is highest among those cheerful people who while not exclusively practicing a sober, object-oriented communication style (SE5) also perceive everyday happenings as important and consider them thoroughly and intensively (SE2). In other words, cheerful individuals who do face things seriously but also communicate humourously will be most likely be able to laugh at their own mishaps and share them with others. While in the US sample (with a restricted age range) the coefficient for SE2 also turned positive after cheerfulness entered the equation, it failed to be significant.

\section{I S C U S S I O N}

Despite their different theoretical backgrounds, the two approaches to humour do overlap very well. In short, trait cheerfulness is strongly related to the more genuine sense of humour facets $(1,4$ to 8$)$ of the SHS and the 'good mood' element of SHS-3. Trait seriousness corresponds to the 'seriousness' and 'playfulness' items of the scales SHS-2 and SHS-3; and bad mood has its SHS-counterpart in the 'negative mood' component of scale SHS-2. While in the SHS both 'seriousness' and 'negative mood' mark humourlessness (or the low pole of sense of humour), it might be better to separate them on the basis of theoretical (the former is more of an attitudinal or mental and the latter of affective nature) and empirical (they form separate and only mildly correlated factors in the item factor analysis) grounds. Also in the STCI, bad mood and seriousness do have a positive but only medium-sized correlation irrespective of whether they are studied as traits or states (Ruch et al., 1996).

There are differences between the approaches as well. McGhee (1996) sees playfulness (and seriousness) to be the foundation of the sense of humour; the activation of a playful attitude triggers the other components. While the fact that 'humour skills' and 'playful vs. serious' indeed formed distinct but correlated factors is compatible with McGhee's assumptions, the question as to the basis of the sense of humour, however, cannot be answered by correlational studies but will have to consider dynamic or processual factors. For example, one will have to change a person's location on the serious-playful dimension 
(leaving the humour skills untrained) and examine whether the activation of a playful attitude or outlook indeed triggers the other components and boosts the overall sense of humour.

There is no such assumption of a dynamic relationship among the STCI constructs; however, cheerfulness, seriousness, and bad mood are considered to be the "temperamental basis" of humour. Thus, it was not attempted to undertake a conceptualization of the "sense of humour" which was regarded as a folk-concept--too vague and fuzzy from a scientific point of view. Rather the approach taken was to define precisely and explicitly some traits considered to be relevant for the domain of behaviour a sense of humour concept should predict. Indeed, although content-saturated humour items were generally avoided in the STCI, validity studies showed that all three constructs were involved in the prediction of humour behaviour (Ruch \& Köhler, in press a). Furthermore, self-reported habitual individual differences in humour (as typically assessed in sense of humour scales) could be predicted as well, and joint factor analyses--like the one in the present study--showed that the three traits serve well as markers for the dimensions underlying the sense of humour.

Thus, the sense of humour (in the broader meaning of the term) can be seen as a descriptive construct composed of components, such as cheerfulness, seriousness, and bad mood (and perhaps further dimensions yet to be identified). The study provided some support for the proposed relationship between cheerfulness and the sense of humour (in the narrow meaning of the term). In both samples, trait cheerfulness correlated significantly with 'laughing at yourself'. Thus, individuals high in trait cheerfulness indicated that they have no trouble poking fun at their own physical qualities, often find humour in their own embarrassing incidents or personal blunders and tell others the funny side of it, have no difficulty telling jokes in which they are the butt or laughing at such jokes. Inasmuch as the present assessment of 'laughing at yourself' is a valid indicator of the sense of humour as understood by Lersch (1962), this can be regarded as compatible with the hypothesis that trait cheerfulness is a factor underlying the sense of humour.

However, one has to bear in mind that current of sense of humour instruments are not based on these older conceptualizations of the construct and are in part even incompatible with them. While the expression of 'laughing at oneself' can be meant metaphorically to denote that one is able to see and accept one's own shortcomings and mishaps and does not exclude them from joking or humour, one does not literally have to 'laugh' at them or often joke about them. Typically, in these conceptualizations the person of humour does not laugh; he or she smiles, most often even "inwardly". The inclusion of 'laughter' in the formulation of items might add too much variance relating to laughter propensity and thus override the variance related to the composed and tolerant attitude. Thus, a concept meant to be a world view in theories may turn out to be an affective construct in measurement instruments. Furthermore, 'laughing at yourself' is only one indicator of sense of humour; and a better test of the hypothesis needs a scale that gives a broader conceptualization of sense of humour as a 
world view.

Finally, for a more adequate testing of the Hehlmann-Lersch hypothesis that certain factors (like negative life experiences and acquired insights into the human nature and human existence) bring up the humourous attitude or world view among individuals with a cheerful temperament, several further issues need to be considered. First, preferably a longitudinal study is needed with trait cheerfulness assessed prior to the life events (so that it is not itself affected by them) and humour (in the more narrow sense) assessed after these life events. Second, such a hypothesis might be best tested exclusively among a sample of older subjects (i.e. individuals who have been exposed to life experiences and have had a chance to acquire wisdom) rather than college students. Indeed, the cross-sectional studies of age effects have shown that while most facets of cheerfulness remain relatively stable across the life span, facet $\mathrm{CH} 3$ (cheerful composure, the humour equivalent in the STCI) increases steadily after age forty. Likewise, the inspection of the normative sample of the STCI shows that while generally only very few people are high in both cheerfulness and seriousness, there is a disproportionately high number of older subjects among them. Thus, perhaps the hypothesis that more profound aspects of the sense of humour are correlated positively with cheerfulness and seriousness would yield more support than in the present study.

The view that at least two factors are necessary for a humourous attitude to develop--a cheerful temperament and prior (successfully mastered) adverse life experiences--implies, of course, that cheerfulness and humour are different constructs. Without such consideration, the high correlation found between trait cheerfulness and the SHS total score would inevitably raise the question of whether there is an identity of trait cheerfulness and sense of humour-whether the problem would be solved by just relabeling the cheerfulness scale as one measuring sense of humour, or vice versa, replacing sense of humour by trait cheerfulness. However, the present study and previous ones largely overestimate the role of cheerfulness in humour. This is due to the fact that conceptualizations of the sense of humour give too much weight to the affective-expressive and social qualities, and, hence, there is much conceptual overlap with cheerfulness. A sense of humour conceptualized as an attitude or world view should not be so strongly related to affect, thus leaving room for additional, moderating variables to be involved.

Acknowledgments - The preparation of this manuscript was facilitated by a DFG-grant $(\mathrm{Ru} 480 / 5-2)$ to the senior author. Special thanks to Claudia Esser and Christoph van Thriel for collecting parts of the German data. Correspondence should be addressed to Willibald Ruch, Department of Psychology, University of Düsseldorf, Universitätsstraße 1, 40225 Düsseldorf, Germany.

\section{R E F E R E N C E S}

Craik, K., Lampert, M. D. \& Nelson, A. (1996). Sense of humor styles of everyday humorous conduct. Humor, 9 , 273-302.

Hehlmann, W. (1968). Wörterbuch der Psychologie. Stuttgart: Kröner. 
Köhler, G. \& Ruch, W. (1996). Sources of variance in current sense of humor inventories: How much substance, how much method variance? Humor, 9, 363-397.

Lersch, P. (1962). Aufbau der Person. München: Barth.

McGhee, P. E. (1979). Humor: Its origin and development. New York: Freeman.

McGhee, P. E. (1996). The laughter remedy. Health, healing and the amuse system. Dubuque, IA: Kendall/Hunt.

Ruch, W. \& Köhler, G. (in press a). A temperament approach to humor. In: W. Ruch (Ed.), The "sense of humor": Explorations of a personality characteristic. Berlin, Germany: Mouton de Gruyter.

Ruch, W. \& Köhler, G. (in press b). The measurement of state and trait cheerfulness. In: I. Mervielde, I. Deary, F. De Fruyt \& F. Ostendorf (Eds.), Personality Psychology in Europe: Theoretical and Empirical Developments, Vol. 8, Lisse: Svets and Zeitlinger.

Ruch, W., Köhler, G. \& van Thriel, C. (1996). Assessing the "humorous temperament": Construction of the facet and standard trait forms of the State-Trait-CheerfulnessInventory - STCI. Humor, 9, 303-339. 
T A B LE HE A D IN G S

Table 1. Psychometric characteristics of the scales in the American and German samples

Table 2. Joint factor analysis of the SHS and STCI scales in the American and German samples 
Table 1. Psychometric characteristics of the scales in the American and German samples

\begin{tabular}{|c|c|c|c|c|c|c|}
\hline \multirow[b]{2}{*}{ Scales } & \multicolumn{3}{|c|}{ US sample } & \multicolumn{3}{|c|}{ German sample } \\
\hline & $\underline{\text { Mean }}$ & $\underline{\mathrm{SD}}$ & $\alpha$ & $\underline{\text { Mean }}$ & $\underline{\mathrm{SD}}$ & $\alpha$ \\
\hline \multicolumn{7}{|l|}{ SHS } \\
\hline Enjoyment of humour & 15.97 & 2.53 & 0.57 & 14.23 & 2.75 & 0.65 \\
\hline Seriousness and negative mood & 9.94 & 2.71 & 0.59 & 9.60 & 2.90 & 0.75 \\
\hline Playfulness and positive mood & 15.52 & 2.65 & 0.70 & 15.19 & 2.43 & 0.65 \\
\hline Laughter & 14.44 & 2.79 & 0.58 & 13.73 & 2.52 & 0.56 \\
\hline Verbal humour & 14.88 & 3.03 & 0.72 & 12.52 & 3.15 & 0.75 \\
\hline Finding humour in everyday life & 16.85 & 2.39 & 0.77 & 14.84 & 2.50 & 0.74 \\
\hline Laughing at yourself & 15.33 & 3.14 & 0.80 & 14.11 & 3.11 & 0.78 \\
\hline Humour under stress & 14.34 & 3.04 & 0.69 & 13.06 & 2.96 & 0.72 \\
\hline SHS-Total sense of humour & 122.40 & 16.30 & 0.92 & 113.07 & 15.12 & 0.90 \\
\hline \multicolumn{7}{|l|}{ STCI } \\
\hline STCI-T Cheerfulness & 120.23 & 15.77 & 0.94 & 117.63 & 14.55 & 0.93 \\
\hline STCI-T Seriousness & 85.77 & 14.19 & 0.98 & 93.53 & 14.56 & 0.89 \\
\hline STCI-T Bad Mood & 60.18 & 16.71 & 0.95 & 66.49 & 14.37 & 0.92 \\
\hline
\end{tabular}

Notes. $\underline{\mathrm{N}}=263$ (American) and 151 (German). $\mathrm{a}=$ Coefficient Alpha; SHS = Sense of Humour Scale; STCI-T $=$ State-Trait-Cheerfulness-Inventory. 
Table 2. Joint factor analysis of the SHS and STCI scales in the American and German samples

\begin{tabular}{|c|c|c|c|c|c|c|}
\hline & \multicolumn{2}{|c|}{ Factor 1} & \multicolumn{2}{|c|}{ Factor 2} & \multicolumn{2}{|c|}{ Factor 3} \\
\hline & US & German & US & German & US & German \\
\hline Enjoyment of humour & 0.55 & 0.52 & -0.21 & -0.12 & 0.16 & 0.01 \\
\hline Seriousness and negative mood & -0.06 & -0.01 & 0.08 & 0.12 & 0.50 & 0.76 \\
\hline Playfulness and positive mood & 0.27 & 0.51 & 0.14 & 0.02 & -0.42 & -0.31 \\
\hline Laughter & 0.66 & 0.68 & 0.16 & 0.10 & 0.02 & -0.03 \\
\hline Verbal humour & 0.76 & 0.56 & -0.05 & -0.14 & 0.31 & 0.12 \\
\hline Finding humour in everyday life & 0.74 & 0.72 & -0.01 & 0.06 & 0.16 & 0.03 \\
\hline Laughing at yourself & 0.64 & 0.54 & 0.14 & 0.01 & 0.07 & -0.04 \\
\hline Humour under stress & 0.65 & 0.63 & -0.01 & -0.04 & 0.06 & 0.16 \\
\hline STCI-T CH1 & 0.29 & 0.46 & 0.11 & 0.00 & -0.47 & -0.48 \\
\hline STCI-T CH2 & 0.52 & 0.57 & 0.07 & -0.01 & -0.16 & -0.27 \\
\hline STCI-T CH3 & 0.30 & 0.34 & 0.11 & 0.08 & -0.37 & -0.47 \\
\hline STCI-T CH4 & 0.60 & 0.65 & -0.14 & -0.05 & 0.00 & -0.06 \\
\hline STCI-T CH5 & 0.59 & 0.71 & 0.00 & -0.06 & -0.12 & -0.06 \\
\hline STCI-T SE1 & -0.08 & 0.00 & 0.58 & 0.61 & 0.00 & 0.30 \\
\hline STCI-T SE2 & 0.09 & 0.18 & 0.52 & 0.78 & 0.25 & 0.11 \\
\hline STCI-T SE3 & 0.16 & -0.14 & 0.70 & 0.61 & 0.01 & 0.05 \\
\hline STCI-T SE4 & -0.10 & 0.03 & 0.71 & 0.77 & -0.12 & -0.13 \\
\hline STCI-T SE5 & -0.09 & -0.13 & 0.66 & 0.73 & -0.15 & -0.15 \\
\hline STCI-T SE6 & -0.36 & -0.43 & 0.34 & 0.40 & 0.07 & 0.15 \\
\hline STCI-T BM1 & -0.07 & 0.01 & 0.01 & -0.12 & 0.60 & 0.81 \\
\hline STCI-T BM2 & 0.11 & 0.17 & 0.00 & -0.05 & 0.68 & 0.86 \\
\hline STCI-T BM3 & -0.08 & -0.26 & 0.04 & 0.20 & 0.57 & 0.54 \\
\hline STCI-T BM4 & 0.01 & 0.08 & 0.07 & 0.10 & 0.62 & 0.83 \\
\hline STCI-T BM5 & -0.10 & -0.34 & 0.16 & 0.11 & 0.46 & 0.36 \\
\hline
\end{tabular}


Note. $\underline{\mathrm{N}}=263$ (American) and 151 (German). 


\begin{abstract}
${ }^{1}$ As already indicated by the composite scale labels, these two scales are heterogeneous. A principle components analysis of the 10 items yielded two almost orthogonal factors (explaining 49\% of the variance). One of which combined all playful/serious items and correlated most strongly with seriousness (STCI-T SE; $\underline{r}=-0.53$ ) and less so with trait cheerfulness $(\underline{r}=0.44)$ and trait bad mood (STCI-T BM r $=-0.36)$. The other factor combined items of positive mood/optimism and pessimism/negative mood and correlated with STCI-CH $(\underline{r}=0.47)$ and STCI-T $\mathrm{BM}(\underline{\mathrm{r}}=-0.58 ;$ all df $=261 ; \underline{\mathrm{Ps}}<0.001)$ but not with STCI-T SE $(\underline{\mathrm{r}}=-0.12, \mathrm{P}<0.05)$.
\end{abstract}

